\author{
Research paper
}

\title{
Silk fibroin as a novel coating material for controlled release of theophylline
}

\author{
Oguz Bayraktar*, Özge Malay, Yarkın Özgarip, Ayşegül Batıgün \\ Bioreaction Engineering Laboratory, Department of Chemical Engineering, Izmir Institute of Technology, Gülbahçe Köyü, 35430 Urla-Izmir, Turkey
}

Received 2 November 2004; accepted in revised form 3 February 2005

Available online 1 April 2005

\begin{abstract}
The aim of this study was to explore potential use of the silk fibroin (SF) as an aqueous coating material for theophylline tablets. We have examined the film forming and coating properties of heat-treated fibroin, SF solution having different amounts of polyethylene glycol (PEG) and 1-ethyl-3-(3-dimethyl aminopropyl)carbodiimide (EDC) cross-linked SF. Heat-treated SF material possessed a brittle structure, which resulted in poor film forming and coating properties. The optimum PEG amount in SF solution was determined as $17 \%$ (by weight) for an acceptable film forming and zero order release profile. EDC cross-linked SF has shown a very good film forming and coating property with a potential for sustaining the drug release from coated theophylline tablets. Dissolution data for coated theophylline tablets were analyzed using Ritger and Peppas equation to describe the mechanism of drug release. Drug release from the EDC coated tablets followed zero-order kinetics. Release rate constants were found to be $0.26,0.19,0.16 \% \mathrm{~min}^{-1}$ for single-coated, double coated, and triple coated tablets, respectively. These results clearly demonstrated that silk fibroin has high utility as a novel aqueous coating material for controlled release products.
\end{abstract}

(C) 2005 Elsevier B.V. All rights reserved.

Keywords: Silk fibroin; Theophylline; Aqueous coating; Controlled release; Cross-linking

\section{Introduction}

Oral solid dosage forms for sustained drug release has the major attention amongst all the controlled drug delivery systems due to its conventional usage. Polymeric film coatings have been utilized widely for controlled release of an active substance from pharmaceutical dosage forms because the coated dosage forms enable the sustained and precise release of drug with good reproducibility. The performance of these drug delivery systems is evaluated primarily in terms of their release kinetics and overall ease of administration. Methods that release drug with zero order kinetics (a time-independent rate) for an extended time period are usually considered optimal. While coating with

\footnotetext{
* Corresponding author. Bioreaction Engineering Laboratory, Department of Chemical Engineering, Izmir Institute of Technology, Gülbahçe Köyü, 35430 Urla-Izmir, Turkey. Tel.: +90 232750 6287; fax: +90 232 7506196.

E-mail address: oguzbayraktar@iyte.edu.tr (O. Bayraktar).
}

organic polymeric solutions is still widespread, due to potential environmental safety and toxicity problems and economical concerns associated with some organic solvents, the pharmaceutical industry has been exploring alternatives to organic based tablet coating formulations [1]. Aqueous polymeric solutions have drawn much attention to overcome the problems in organic polymeric solutions. From both academic and industrial point of view it is essential to improve existing coating materials and explore the potential of new materials and coating techniques. Therefore, the pharmaceutical industry expends a considerable amount of resources to produce oral solid dosage forms, to replace solvent-based film coatings with aqueous coating processes [2,3]. Existing aqueous-based coating materials include cellulosic (e.g. cellulose acetate dispersion) and acrylic polymers. Examples of commercially available cellulosic aqueous coating systems are Aquacoat ${ }^{\circledR}$ from FMC Corp., and Surelease ${ }^{\circledR}$ from Colorcon, Inc. [4,5]. Although both type of polymers have good film-forming properties resulting in tough protective coatings, there have been several problems confronted such as unexpected interactions with the active compound, tackiness of the polymeric films causing agglomeration during 
coating, cracking tendency in case of wrong coating composition or brittleness preventing coherent film formation [1-3]. Similar limitations with existing polymeric solvent-based pharmaceutical coatings show that there is still a need to discover new aqueous coating materials with better film-forming characteristics. Due to these reasonings, there is an ongoing research for developing novel coating materials or curing studies on the existing coating polymers. Zein and starch were investigated as coating materials and applied to tablets and pellets with regard to these attempts [6-8].

In this research, potential use of silk fibroin as an aqueous coating material was investigated. Silk fibroin is an attractive natural fibrous polymer produced by the species Bombxy mori $[9,10]$. It is known that besides material for clothing, fibroin has been widely applied to cosmetics, medicine, food and chemical industry [11].

$\mathrm{SF}$, as protein polymer, provides processability in aqueous solutions to obtain material options with differing formats. Therefore, aqueous silk solutions represent a good starting material for the preparation of different kinds of fibroin-based materials, such as film, gel, powder, and membranes [11,12]. Recently, several researchers have investigated SF as one of the promising resources of biotechnology and biomedical materials due to its unique properties including good biocompatibility, biodegradability, and minimal inflammatory reaction [12-14]. It was reported that SF had the potential to find applications in the development of scaffolds in tissue engineering, matrices in controlled drug delivery systems, and biomaterials such as artificial skin substitutes and soft contact lenses [12-17].

Besides its promising applications, SF films have poor mechanical film properties and they are quite hard and brittle in dry state. However, uniqueness of SF is believed to arise from the glycilalanil (GlyAla) repeats, which tend to form the $\beta$ structure under certain conditions and it can be easily modified by several treatments such as heating, immersion in methanol, shearing, blending with natural polymers such as sodium alginate [18], cellulose [19] and chitosan [20], or synthetic polymers such as poly(acrylamide) [21], poly(vinyl alcohol) [22], poly(ethylene glycol) [23] and poly(ethylene oxide) [24], or introducing chemical crosslinking agents [17].

Chemical modifications by using crosslinking reagents are necessarily applied to find more versatile applications of biopolymers by the demonstration of improvements. The commonly used crosslinking agents are aldehydes such as glutaraldehyde and formaldehyde [25-27] or carbodiimides such as dicyclohexyl carbodiimide (DDC) and 1-ethyl-3-(3dimethylaminopropyl) carbodiimide hydrochloride (EDC) [26-35]. In the literature, carbodiimides, known as noncytotoxic and biocompatible crosslinking agents, have been used to modify the properties of the films made from proteins and/or polysaccharides [26-35]. Researchers usually reported that the film forming properties, flexibility and tensile strengths of the prepared films were improved after crosslinking. In this study, a water-soluble carbodiimide EDC was used for an aqueous crosslinking reaction of silk fibroin. There are many studies in literature which had taken the advantage of water soluble EDC with toxicological acceptability such as the crosslinking of collagen/ hyaluronic acid scaffolds with EDC $[32,33]$ and the use of EDC cross-linked gelatin matrices for the macromolecular solute release [28]. To our knowledge, there was no report in the literature on the cross-linking of SF with EDC and application of SF as a film-forming agent for pharmaceutical film coatings.

The focus of the current paper was to explore applications of the silk fibroin as an aqueous coating material for tablets containing theophylline as the model drug. In this study, release kinetics of theophylline tablets coated with three different types of coating materials, heattreated fibroin; fibroin-PEG coating; and EDC-cross-linked fibroin coating, were evaluated.

\section{Materials and methods}

\subsection{Materials}

The silk of Bombyx mori (domestic silkworm) was obtained in reeled form from Bursa Institute for Silkworm Research (Bursa, Turkey). Theophylline (anhydrous) purchased from Sigma Chemical Co. was used as a model drug. Cellulose tubings (Visking) with molecular cut-off 12,000 $14,000 \mathrm{Da}$ were used for dialysis. Polyethylene glycol $(\mathrm{MW}=4000)$ was purchased from Merck. Cross-linking agent used was 1-ethyl-3-(3-dimethyl aminopropyl) carbodiimide hydrochloride obtained from Fluka. $\mathrm{Na}_{2} \mathrm{CO}_{3}$, $\mathrm{CaCl}_{2}, \mathrm{AgNO}_{3}$ and Ethanol were purchased from Sigma Chemical Co.

\subsection{Preparation of aqueous coating solutions}

\subsubsection{SF solution}

The raw silk fibers of Bomyx mori were processed three times (40 min each) in $0.5 \mathrm{wt} \% \mathrm{Na}_{2} \mathrm{CO}_{3}$ solution at 98 $100{ }^{\circ} \mathrm{C}$ to remove sericin (degumming), rinsed with deionized water, and dried at room temperature. The degummed fibroin $(5 \mathrm{~g})$ was dissolved in $100 \mathrm{ml}$ of the ternary solvent, $\mathrm{CaCl}_{2}$-ethanol-water (mole ratio $=1: 2: 8$ ), by stirring at $78{ }^{\circ} \mathrm{C}$ for $2 \mathrm{~h}$. The ratio of degummed silk to ternary solvent was always kept at 1:20 (weight/volume, respectively). The resulting fibroin solution was filtered and dialyzed in a cellulose tube against deionized water for 3 days until dialyzate was tested negative for chloride ion $\left(\mathrm{AgNO}_{3}\right)$. Then the solution was concentrated to $20 \%(\mathrm{w} / \mathrm{v})$ with a rotary evaporator at $37^{\circ} \mathrm{C}, 60 \mathrm{rpm}$.

\subsubsection{SF/PEG solution}

PEG was added to the concentrated fibroin solution in the beaker at changing ratios to improve the film-forming 
properties of SF. After coating the tablets with SF/PEG solution with PEG concentration of $12.5,17$, and $25 \%$ by weight, they were dried at $45^{\circ} \mathrm{C}$ to cause $\beta$ sheet transformation of SF to occur.

\subsubsection{SF/EDC solution}

A volume of $5 \mathrm{ml}$ fibroin solution $20 \%$ (w/v) was mixed with $5 \mathrm{ml} 20 \mathrm{mM}$ EDC in a beaker for $1 \mathrm{~h}$. In this study $\mathrm{N}$-hydroxysuccinimide (NHS) could be used as an enhancer to form more stable crosslinking products [30]. However, even there predicted a slower crosslinking reaction without NHS, it was preliminarily desired to investigate the potential of EDC-cross-linked SF films for tablet coating material and to evaluate the effect of SF-EDC crosslinking on the release studies.

\subsection{Tablet preparation}

Theophylline tablets were prepared by compressing powder form of the drug with the use of hydraulic press operated at $110 \mathrm{MPa}$ pressure. Stainless steel die with a diameter of $1.2 \mathrm{~cm}$ was used to produce $400 \mathrm{mg}$ drug tablets having cylindrical shapes.

\subsection{Dip-coating}

The coating solutions as described in Section 2.2 were used to coat the surface of theophylline tablets via a dipcoating method (dip-coater device, Nima Technology Ltd, England). The coating process places a thin tight coating over the compressed tablets. The tablets coated with SF solution and SF/PEG solution were cured at a temperature of $45^{\circ} \mathrm{C}$ for $48 \mathrm{~h}$. The tablets coated with SF/EDC solution (described in Section 2.4) were dried at room temperature for $48 \mathrm{~h}$. Double-coated and triple-coated tablets were prepared by repeating the above coating procedure. The coated tablets were then stored in closed, light-protected glass vials until further experimentation.

\subsection{Dissolution studies}

The in vitro dissolution studies were performed according to the United States Pharmacopeia XXIII (USP XXIII) dissolution methodology using a dissolution device (Caleve 10ST). A volume of $900 \mathrm{ml}$ dissolution medium was placed in the vessel. Temperature $\left(37^{\circ} \mathrm{C}\right)$ of the dissolution medium, paddle rotation speed $(50 \mathrm{rpm})$ and dissolution time (5-6 h) was adjusted by the control unit of the device.

A drug may be expected to remain in stomach for $2-4 \mathrm{~h}$ (gastric emptying time) and in the small intestines for $4-10 \mathrm{~h}$. The $\mathrm{pH}$ of the stomach varies from 1 to 3 and in intestines colon this value is between $\mathrm{pH} 7$ and $\mathrm{pH}$ 8. To simulate the gastro intestinal tract (GIT), the $\mathrm{pH}$ of the dissolution medium was kept at 3 during the first $3.5 \mathrm{~h}$ of dissolution test, then, it was increased to 7.4 and was kept at that value until the end of the test. In the preparation of the dissolution medium, $8.5 \mathrm{v} \%$ phosphoric acid was added to the $900 \mathrm{ml}$ distilled water to reduce $\mathrm{pH}$ to the value of 3 . After $3.5 \mathrm{~h}$, the $\mathrm{pH}$ of the medium was increased to 7.4 by adding 5.3 $\mathrm{M} \mathrm{NaOH}$ to the solution. During dissolution test, samples were withdrawn from the dissolution medium at certain times and concentration of theophylline in the release medium was determined at $272 \mathrm{~nm}$ by using a spectrophotometer (Shimadzu, UV-1601). Each dissolution test was conducted on three tablets and the mean of the results was calculated.

The release data of drug from coated tablets was fitted by using Eq. (1) [36] in order to propose the possible release mechanism.

$\frac{M_{t}}{M_{\infty}}=K t^{n}$

Where $M_{t}$ corresponds to the amount of drug released at time $t ; M_{\infty}$ is the total amount of drug that must be released at infinite time; $K$ is a release constant and is related to the structural and geometric properties of the dosage form; $n$ is the release exponent indicating the type of drug release mechanism. This equation has been used frequently in the literature, due to its utility in describing the relative importance of Fickian $(n=0.5)$ and zero-order $(n=1)$ mechanism in drug diffusion. In zero-order kinetics, the release rate remains constant until the entire active ingredient has been delivered. The term zero-order means time-independent rate and so as being independent of quantity of drug remaining. The $t_{50}$ is the time at which $50 \%$ of the drug was released from the tablet.

\subsection{Characterization}

The morphology of the surfaces of the coated tablets was examined by scanning electron microscopy (SEM) (Philips, XL-30S FG). Cross-sectional SEM images of the coated tablets were used to determine the overall coating thickness. FTIR and XRD analyses were performed for EDC crosslinked SF film coatings to confirm the structural changes.

\section{Results and discussion}

\subsection{Coating with heat-treated $S F$}

Processing conditions such as solution concentration, solution temperature, drying temperature, drying time, the presence of electric field, $\mathrm{pH}$, the presence of certain enzymes and type of solvent can be used to control the molecular conformation of the resulting SF membrane [37]. Silk fibroin films prepared by casting the aqueous protein solution and drying at $25^{\circ} \mathrm{C}$ are soluble in water [38]. Such films have a micro phase-separated structure consisting of crystal and amorphous regions. It is found that higher processing temperature $\left(45^{\circ} \mathrm{C}\right)$ leads the amorphous random 


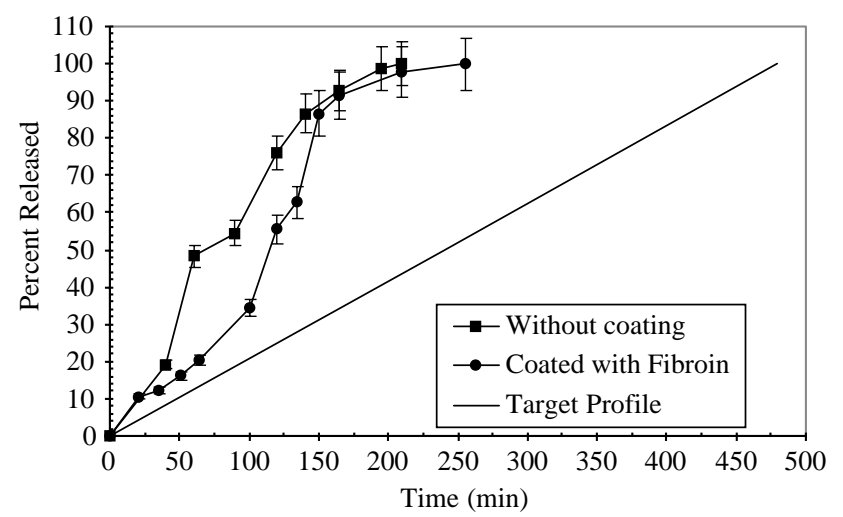

Fig. 1. Release profile of the theophylline tablet coated with heat-treated SF.

coil structure in the membranes to convert to $\beta$-pleated structure [38]. This structure produces morphology with aggregated fibrils. The starting solution concentration and casting temperature are of critical importance for the structure of the fabricated films [39]. Insolubilization of fibroin coating around the tablet is required to achieve sustained release of theophylline. After coating the prepared theophylline tablets using SF solution the tablets were dried at $45^{\circ} \mathrm{C}$ in a static oven in order to convert the structure from random coil to $\beta$-sheet form. The conformational change in SF structure was investigated earlier in the literature [37-39]. By achieving $\beta$-sheet transformation of the silk fibroin, insoluble membranes could be obtained.
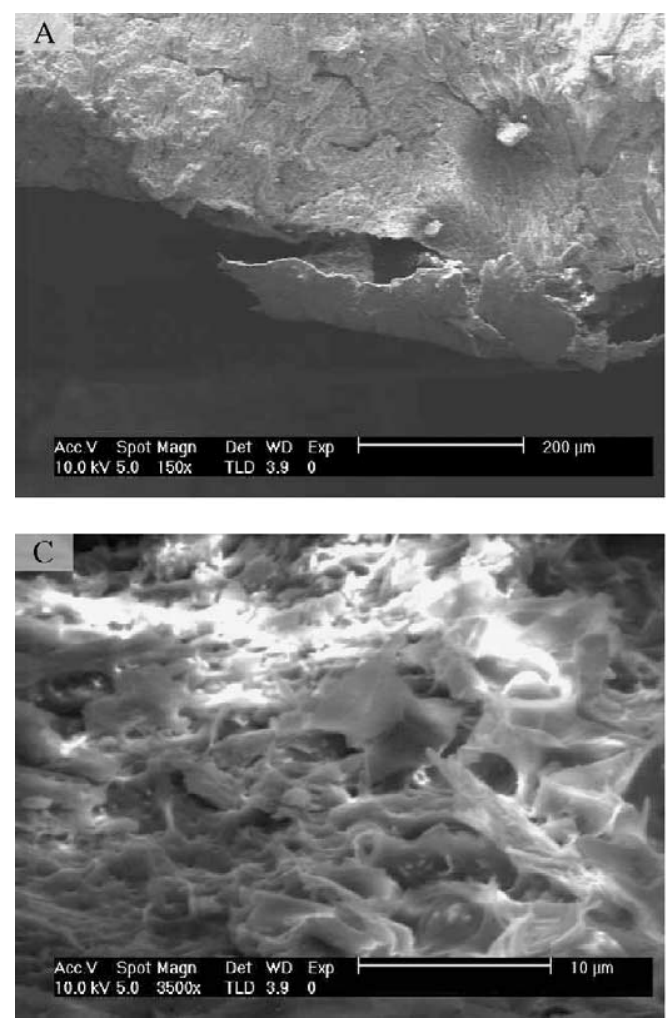

To investigate the drug release kinetics, dissolution tests of the tablets coated with heat-treated silk fibroin were performed. The release profiles of the prepared tablets have been interpreted according to the target profile suggested by Parab et al. [40]. The release profiles of uncoated and heattreated silk fibroin coated theophylline tablets and the target release profile are shown in Fig. 1. Dissolution data of uncoated theophylline tablet showed $100 \%$ drug release at the end of $210 \mathrm{~min}$. As seen from Fig. 1, release profile was far from the desired target profile. To achieve sustained release tablets were coated with heat-treated silk fibroin. For this case drug release was sustained to a certain extent up to $100 \mathrm{~min}$. Only $34 \%$ of the theophylline released showed a linear release pattern, after that an anomalous or diffusion release profile was observed. This result was due to partial removal of SF coating around the tablet at the $100 \mathrm{~min}$ of the dissolution test. The remaining insoluble fibroin coating has slowed the release, but this was not good enough to obtain a release profile similar to the target linear profile. The $K, n$, values and regression coefficients of the curves for the tablet coated with heat-treated silk fibroin were evaluated for two regions. In the first region, which is up to $34 \%$ drug release, the diffusion occurred through the channels of the coating and drug release mechanism could be described by zero order kinetics $\left(K=0.34 \% \min ^{-1}, n=0.97, R^{2}=0.98\right)$. In the second region after the coating around the tablet was partially peeled off, the release occurred with relatively less diffusional barrier. Therefore, release rate was enhanced
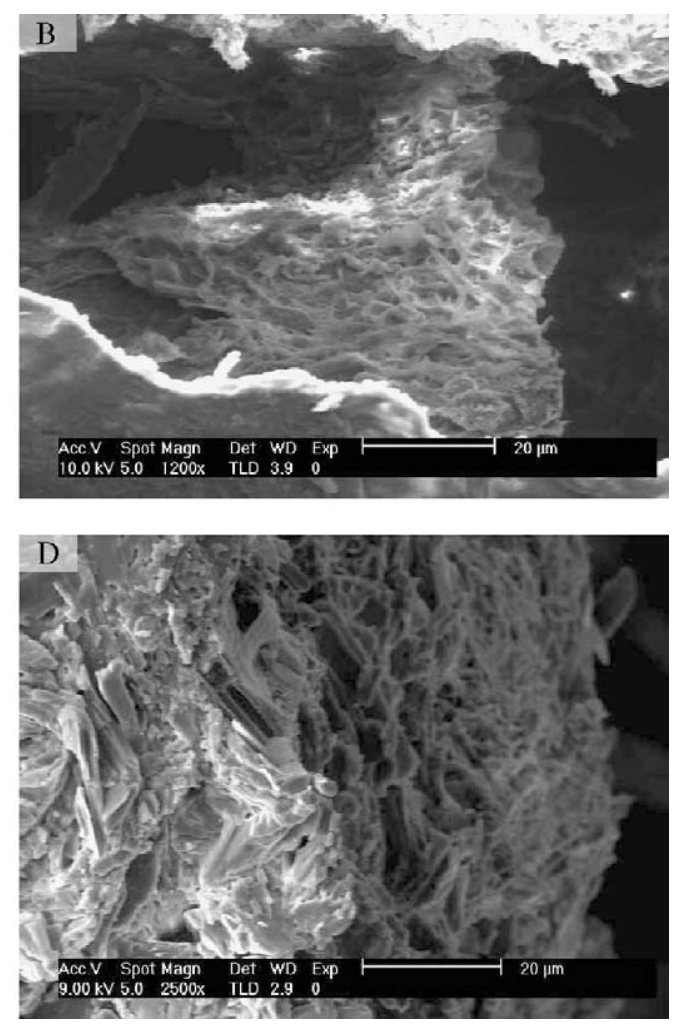

Fig. 2. SEM micrographs of theophylline tablets coated with heat-treated silk fibroin. 


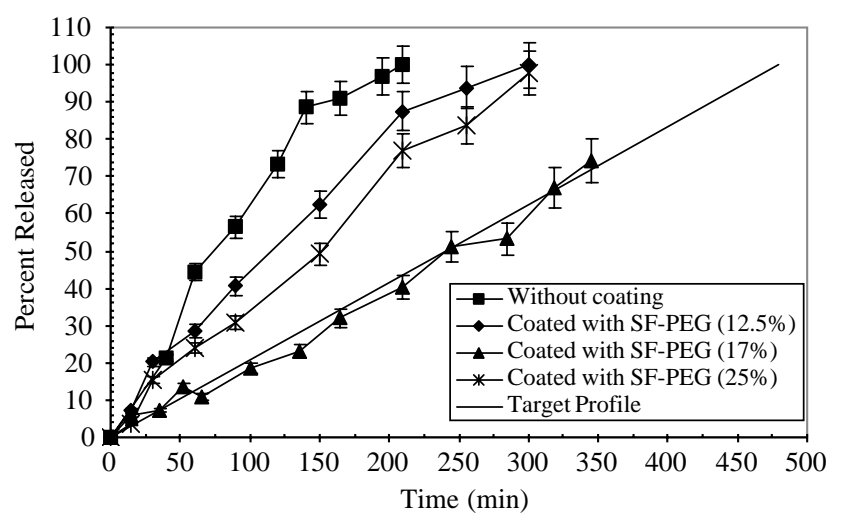

Fig. 3. Influence of PEG concentration on the release profile of theophylline.

and it was comparable to that of uncoated tablet after $150 \mathrm{~min}$ (Fig. 1).

Examination of the tablet coating by scanning electron microscopy (SEM) revealed poor coating comprised of numerous surface defects and cracks in the film structure as shown in Fig. 2a and b. As shown in Fig. 2c and d the heattreated fibrous coating also have a surface with varying porosity and channels where diffusion mechanism occurred within these channels. Since the heat-treated silk fibroin coating possessed a brittle structure, which probably cause poor film forming, and poor interaction between SF coating and theophylline particles (Fig. 2b), fibroin films in dry state become unsuitable for practical use. In order to improve film-making property of SF, PEG was used as a plasticizer in the SF coating solutions.

\subsection{Coating with SF/PEG solution}

Heat-treated fibroin coating on the surface of tablets exhibited severe brittleness and cracking. This demonstrated the need for a plasticizer. PEG was found to be compatible with the fibroin solution since both are water soluble. SF-PEG blend was used as a tablet coating solution. The kinetics of drug release was investigated, after coating theophylline tablets with the SF solution having different amount of PEG. The release profiles obtained can be seen in Fig. 3. While the uncoated tablet dissolved almost completely at the end of $210 \mathrm{~min}$, the tablets coated with the SF solution having 12.5 and 25\% PEG dissolved completely at the end of $300 \mathrm{~min}$. The tablet coated with SF solution containing $17 \%$ PEG required a longer release time $\left(t_{50}=245 \mathrm{~min}\right.$ for $50 \%$ drug release $)$ and release rate was slower than the others. The tablets coated with SF solution containing $12.5 \%\left(K=0.45 \% \mathrm{~min}^{-1} ; n=0.98\right), 17 \%(K=$ $\left.0.20 \% \mathrm{~min}^{-1} ; n=0.98\right)$ and $25 \%\left(K=0.33 \% \mathrm{~min}^{-1} ; n=1\right)$ PEG presented zero order release mechanism with the regression coefficients $\left(R^{2}\right)$ values of $0.98,0.98,099$, respectively. The best release profile was observed with the tablet coated with SF solution containing 17\% PEG. After blending PEG with aqueous fibroin solution, PEG

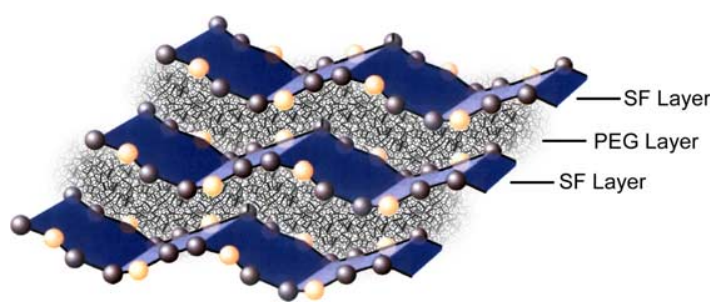

Fig. 4. Model for the formation of SF sheet planes including ductile PEG chains.

chains may form a PEG-rich phase separated from the SF domains. The heat treatment initiates the formation of $\beta$ sheets. PEG chains can be captured between $\beta$-sheet planes without hindering the formation of $\beta$-sheet planes. The improved mechanical properties of SF-PEG coating could be explained by supposing that the sliding between SF sheets planes due to the ductile PEG-rich phases (Fig. 4). Above certain amount of PEG concentration in the SF coating solution (For this case, 17\% PEG), the formation of $\beta$-sheet planes could be hindered and the layered structure of SF-PEG film, which was also speculated by other researchers [23], cannot be formed. Therefore the drug might diffuse more rapidly above critical PEG ratios. The incorporation of plasticizers primarily aims at reducing the brittleness of the polymeric films [41].

\subsection{Coating with EDC cross-linked SF}

The aim of this part was to use EDC cross-linked fibroin as a coating material for sustained release of theophylline. Carbodiimides are zero-length cross-linkers and affect direct coupling between carboxylates $(-\mathrm{COOH})$ and primary amines $\left(-\mathrm{NH}_{2}\right)$ to form stable amide bonds [30]. As mentioned in Section 3.1, the heat-treated fibroin tablet coating had poor mechanical film properties and they were quite brittle. It was observed that cross-linking of SF with EDC made the membrane flexible $[42,43]$.

The dissolution tests were performed for the tablets coated with EDC cross-linked silk fibroin. Fig. 5 shows

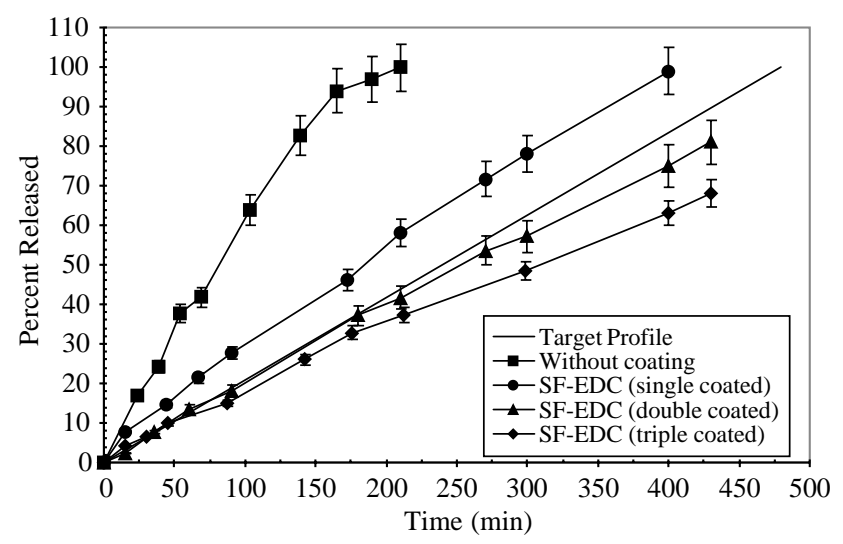

Fig. 5. Influence of coating thickness on the release profile of theophylline tablets coated with EDC cross-linked SF. 
the release profiles of theophylline from single-coated, double-coated, and triple-coated tablets. Multiple coating allowed us to change the thickness of the coating on the tablets in order to observe the effect of coating thickness on the release profile of theophylline. The release profiles of the tablets coated with EDC cross-linked fibroin were compared with that of the uncoated theophylline tablet and target release profile as seen in Fig. 5. As shown in this figure sustained release profiles were achieved for three samples coated with EDC cross-linked fibroin solution since the EDC cross-linked SF membrane prevented rapid diffusion of the drug. It was observed that resistance to transport of drug increased with increasing the length of diffusion path, in other words, increasing the number of coatings. The release rate constants of coated tablets were much smaller than uncoated tablets $\left(K=0.60 \% \mathrm{~min}^{-1}, R^{2}=0.99\right)$. Release rate constants were found to be $0.26,0.19$, $0.16 \% \min ^{-1}$ with the regression coefficient $\left(R^{2}\right)$ value of 0.99 for single-coated, double coated, triple coated tablets, respectively. The release rate of theophylline from coated tablets was significantly decreased due to more barrier hindrance by thicker coating materials. The thickness of the film influences the rate of dissolution of the drug. For this reason thickness is an important factor. As shown in Fig. 5, the double-coated tablet is more similar to the target release profile than the others. When the tablets coated with crosslinked silk fibroin solution, it not only reached a sustained release profile but also followed a zero order drug release mechanism with $n$ values close to 1 .

SEM micrographs of the EDC cross-linked fibroin coated tablet are shown in Fig. 6. These micrographs were obtained to observe the morphology of the tablet coating and to determine the coating thickness. SEM micrographs of the double-coated tablets at different magnifications were obtained in order to observe morphology of the crosssection of this sample. Porous structure of the coating can be seen in Fig. 6. The coating thicknesses were measured at various parts of the each tablet's cross-section and the average values of them were taken. The average coating thickness was measured as $26,57,83 \mu \mathrm{m}$ for single coated, double coated and triple coated tablets, respectively. As expected the release rate was inversely proportional to the thickness of the coatings. The $50 \%$ of drug was released from uncoated tablet within $83 \mathrm{~min}\left(t_{50}=83 \mathrm{~min}\right) . t_{50}$ values were determined as 185,250 , and $306 \mathrm{~min}$ for single coated, double coated and triple coated tablets, respectively. Since resistance to transport of drug increased with increasing the length of diffusion path, the decrease in release rate with increasing number of coating was an expected result.

FT-IR spectroscopy was performed and IR spectra of the regenerated SF films are shown in Fig. 7. The structural changes caused by the EDC cross-linking can be revealed by analyzing the amide I, II, III bands in IR spectroscopy. It is well established for fibroin and other proteins that the peak
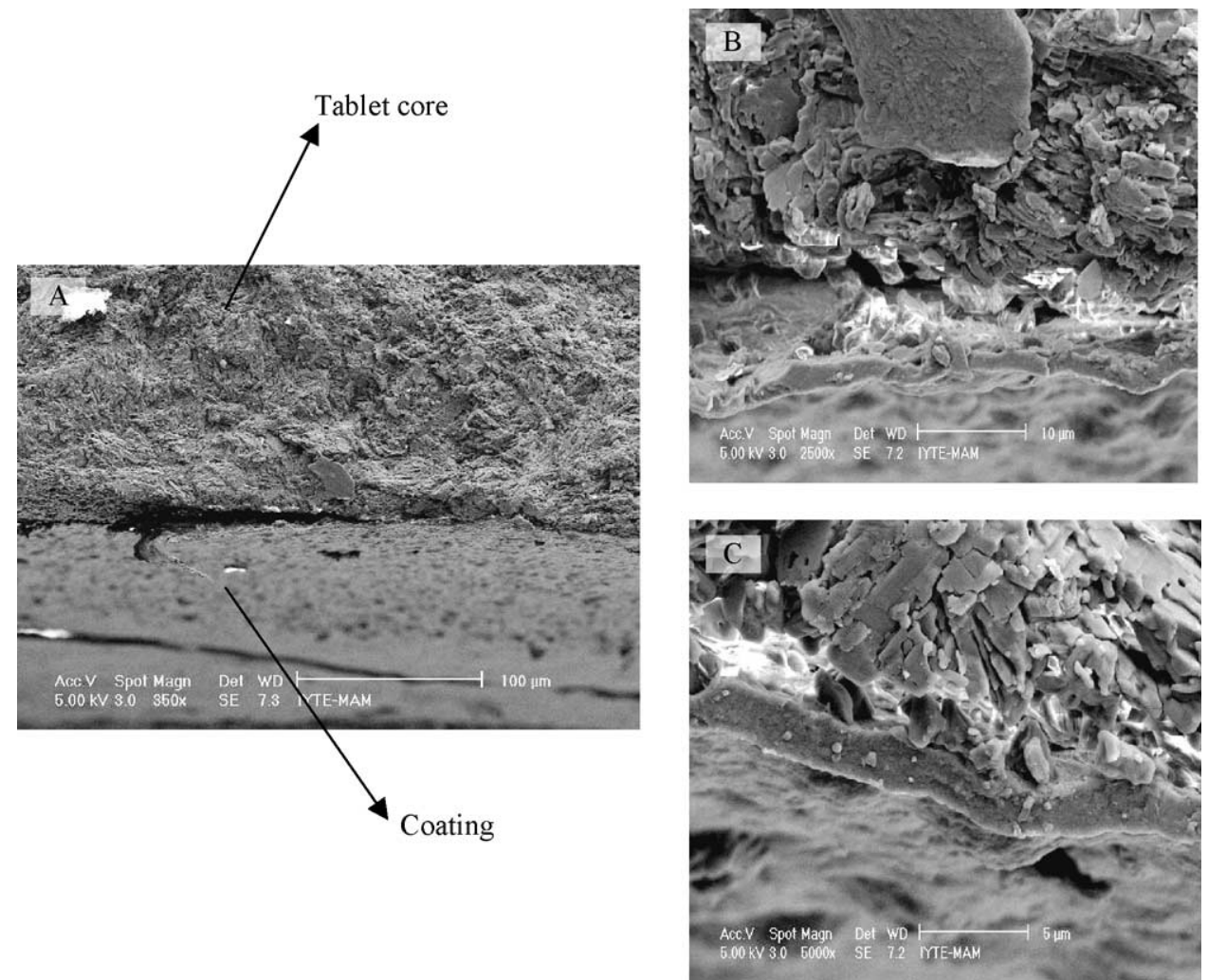

Fig. 6. SEM micrographs of theophylline tablets coated with EDC crosslinked SF. 

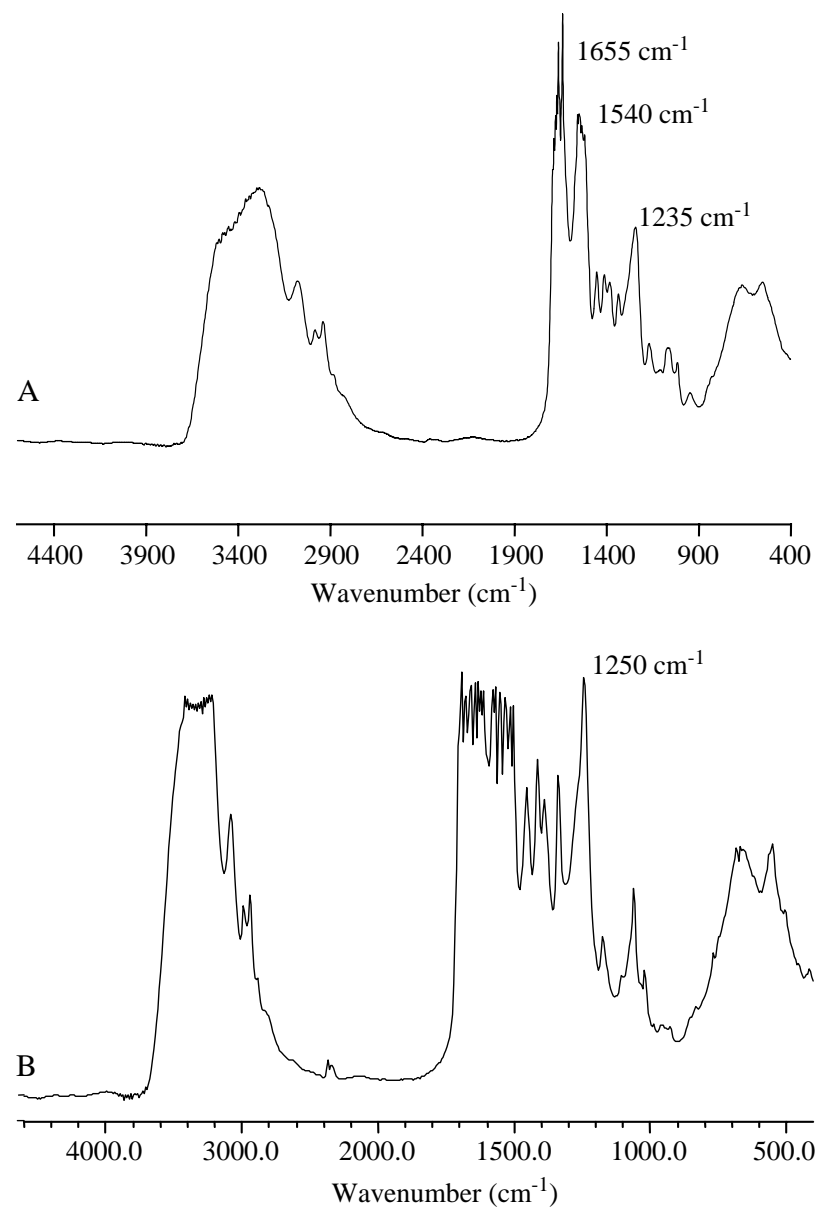

Fig. 7. FT-IR spectra of SF film (A) and EDC crosslinked SF film (B).

position of absorption frequency is quite sensitive to the secondary structure [44]. The vibrational transition bands of $\mathrm{C}=\mathrm{O}$ stretching $\left(1655 \mathrm{~cm}^{-1}\right.$, amide $\left.\mathrm{I}\right), \mathrm{N}-\mathrm{H}$ de-formation and $\mathrm{C}-\mathrm{N}$ stretching $\left(1540 \mathrm{~cm}^{-1}\right.$, amide II), and $\mathrm{C}-\mathrm{N}$ stretching and $\mathrm{N}-\mathrm{H}$ deformation $\left(1250 \mathrm{~cm}^{-1}\right.$, amide III) are seen in the figure. Fig. 7 shows the FT-IR spectra of a fibroin film (Fig. 7a), and the film after cross-linking with EDC (Fig. 7b). The fibroin film showed strong absorption bands at 1655 (amide I), 1540 (amide II), and $1235 \mathrm{~cm}^{-1}$ (amide III), attributed to the random coil conformation (Fig. 7a). In Fig. 7b, spectral changes induced by the EDC cross-linking are recognized. The spectrum before the crosslinking with EDC is apparently ascribable to the random-coil structure. With the EDC cross-linking, the most obvious feature of the $\beta$-sheet structure in IR spectroscopy is the strong absorption band at $1250 \mathrm{~cm}^{-1}$ in the amide III band [44]. Formation of amide bond between carboxylic acid and amino groups of gelatin after cross-linking with EDC was reported in the literature [26]. This band was clearly detected for the amide III band of the film after EDC cross-linking. This result suggested that the conformational change of SF occurred from the random coil to the $\beta$-sheet structure due to the cross-linking with EDC. The spectral changes agree well with a result reported previously [44].
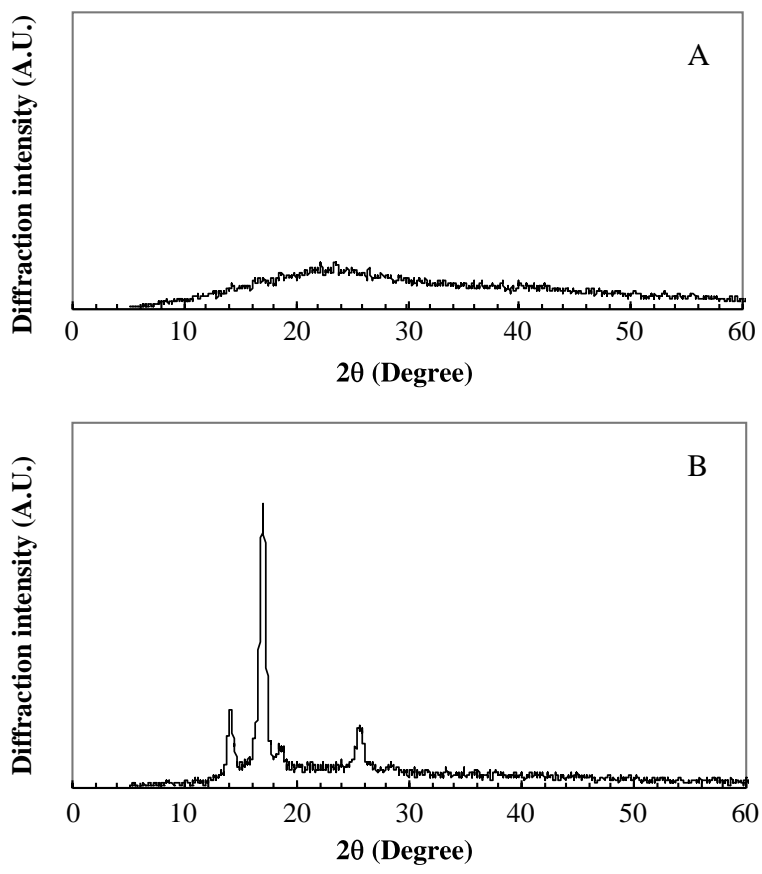

Fig. 8. X-ray diffraction patterns of SF film (A) and EDC crosslinked SF film (B).

XRD method has been mainly used to study crystalline structure, which affects various properties in solid state. The $\mathrm{X}$-ray diffraction patterns of SF film from aqueous solution and EDC cross-linked SF film are shown in Fig. 8. The Xray diffraction pattern for the SF film showed a broad peak with a maximum at $2 \theta=20^{\circ}$.(Fig. $8 \mathrm{a}$ ), corresponding to the typical characteristics diffraction pattern of amorphous silk fibroin. According to the Bragg's equation, $2 \mathrm{~d} \sin \theta=n \lambda$, where $n$ is an order of the reflection (assigned to 1), $\lambda$ is the wavelength of $\mathrm{Cu} \mathrm{K}_{\alpha}$ radiation $(=1.542 \AA)$, and $\theta$ is an incident angle, the distance $(d)$ between the repeating units was $4.44 \AA$. This pattern was quite similar to the results reported in the literature [22]. The EDC cross-linked SF film showed sharp diffraction peaks at $2 \theta=14.3,17.0$, and $25.6^{\circ}$, corresponding to the crystalline spacing of $6.19,5.22$, and $3.48 \AA$, respectively (Fig. 8b). The insolubility property and the crystal structure finding are consistent with the literature [10,37-39]. It was, thus, confirmed by both FTIR spectra and X-ray diffraction that the secondary structure of fibroin molecules changed to $\beta$-sheets.

\section{Conclusions}

Silk fibroin can be considered as a potential aqueous film coating agent to be used for solid pharmaceuticals. Silk fibroin film-coated tablets could be easily prepared without any sophisticate equipment. Hence, this would also be better than the conventional organic-based coating technique, which caused a polluted environment and was toxic to humans. The EDC cross-linked silk fibroin exhibited 
prospectively suitable properties for zero order release of the drug. The investigated SF coating material therefore merits further study in the design of film-coated sustained drug delivery devices.

\section{Acknowledgements}

Financial support from the Izmir Institute of Technology is gratefully acknowledged. Support to Yarkın Özgarip from Diper Chemicals Inc. (Kemalpasa, Turkey) during the period of this work is also acknowledged. We express our thanks to Mr. Emre Kuduğ for his help in the laboratory and to Professor Devrim Balköse for her valuable suggestions during this study.

\section{References}

[1] J.W. McGinity (Ed.), Aqueous Polymeric Coatings For Pharmaceutical Dosage Forms, Marcel Dekker, New York, 1997, pp. 177-225.

[2] M. Tarvainen, R. Sutinen, S. Peltonen, P. Tiihonen, P. Paronen, Starch acetate-A novel film-forming polymer for pharmaceutical coatings, J. Pharm. Sci. 91 (2002) 282-289.

[3] M. Tarvainen, S. Peltonen, H. Mikkonen, M. Elovaara, M. Tuunainen, P. Paronen, J. Ketolainen, R. Sutinen, Aqueous starch acetate dispersion as a novel coating material for controlled release products, J. Controlled Release 96 (2004) 179-191.

[4] S.V. Sastry, W. Wilber, I.K. Reddy, M.A. Khan, Aqueous-based polymeric dispersion: preparation and characterization of cellulose acetate pseudolatex, Int. J. Pharm. 165 (1998) 175-189.

[5] R.-K. Chang, C.H. Hsiao, J.R. Robinson, A review of aqueous coating techniques and preliminary data on release from a theophylline product, Pharm. Technol. 3 (1987) 56-68.

[6] P.B. O’Donnel, C. Wu, J. Wang, L. Wang, B. Oshlack, M. Chasin, R. Bodmeier, J.W. McGinity, Aqueous pseudolatex of zein for film coating of solid dosage forms, Eur. J. Pharm. Biopharm. 43 (1997) $83-89$.

[7] K. Krogars, O. Antikainen, J. Heinämäki, N. Laitinen, J. Yliruusi, Tablet film-coating with amylose-rich maize starch, Eur. J. Pharm. Sci. 17 (2002) 23-30.

[8] P. Palviainen, J. Heinämäki, P. Myllärinen, R. Lahtinen, J. Yliruusi, P. Forssell, Corn starches as film formers in aqueous-based film coating, Pharm. Dev. Technol. 6 (2001) 351-359.

[9] H. Yamada, H. Nakao, Y. Takasu, K. Tsubouchi, Preparation of undegraded native molecular fibroin solution from silkworm cocoons, Mater. Sci. Eng. C 14 (2001) 41-46.

[10] D. Balköse, Investigation of some physico-chemical properties of natural and modified silk fibroin, Associate professorship dissertation (Doçentlik tezi), Ege University, Izmir, Turkey, 1982.

[11] Y.-Q. Zhang, Natural silk fibroin as a support for enzyme immobilization, Biotechnol. Adv. 16 (1998) 961-971.

[12] G.H. Altman, F. Diaz, C. Jakuba, T. Calabro, R.L. Horan, J. Chen, H. Lu, J. Richmond, D.L. Kaplan, Silk-based biomaterials, Biomaterials 24 (2003) 401-416.

[13] B. Panilaitis, G.H. Altman, J. Chen, H.-J. Jin, V. Karageorgiou, D.L. Kaplan, Macrophage responses to silk, Biomaterials 24 (2003) 3079-3085.

[14] H.-J. Jin, J. Chen, V. Karageorgiou, G.H. Altman, D.L. Kaplan, Human bone marrow stromal cell responses on electrospun silk fibroin mats, Biomaterials 25 (2004) 1039-1047.
[15] M. Tsukada, G. Freddi, N. Minoura, G. Allara, Preparation and application of porous silk fibroin materials, J. Appl. Polym. Sci. 54 (1994) 507-514.

[16] H. Katayama, M. Issiki, H. Yoshitomi, Application of fibroin in controlled release tablets containing theophylline, Biol. Pharm. Bull. 23 (10) (2000) 1229-1234.

[17] R. Rujiravanit, S. Kruaykitanon, A.M. Jamieson, S. Tokura, Preparation of cross-linked chitosan/silk fibroin blend films for drug delivery system, Macromol. Biosci. 3 (10) (2003) 604-611.

[18] C.X. Liang, K. Hirabayashi, Improvements of the physical properties of fibroin membranes with sodium alginate, J. Appl. Polym. Sci. 45 (1992) 1937-1943.

[19] G. Freddi, M. Romano, M.R. Massafra, M. Tsukada, Silk fibroin/cellulose blend films: Preparation, structure and physical properties, J. Appl. Polym. Sci. 56 (1995) 1537-1545.

[20] X. Chen, W. Li, T. Yu, Conformation transition of silk fibroin induced by blending chitosan, J. Polym. Sci. 35 (1997) 2293-2296.

[21] G. Freddi, M. Tsukada, S. Beretta, Structural and physical properties of silk fibroin/polyacrylamide blend films, J. Appl. Polym. Sci. 17 (1999) 1563-1571.

[22] M. Li, N. Minoura, L. Dai, L. Zhang, Preparation of porous poly(vinyl alcohol)-silk fibroin (PVA/SF) blend membranes, Macromol. Mater. Eng. 286 (2001) 529-534.

[23] Y. Gotoh, M. Tsukada, T. Baba, N. Minoura, Physical properties and structure of poly(ethylene glycol)-silk fibroin conjugate films, Polymer 38 (1997) 487-490.

[24] H.-J. Jin, J. Park, R. Valuzzi, P. Cebe, D.L. Kaplan, Biomaterial films of Bombyx mori silk fibroin with poly(ethylene oxide), Biomacromolecules 5 (2004) 711-717.

[25] K. Tomihata, Y. Ikada, Cross-linking of hyaluronic acid with glutaraldehyde, J. Polym. Sci. 35 (1997) 3553-3559.

[26] C.M. Ofner, W.A. Bubnis, Chemical and swelling evaluations of amino group cross-linking on gelatin and modified gelatin matrices, Pharm. Res. 13 (12) (1996) 1821-1827.

[27] S. Kim, D.J. Sessa, J.W. Lawton, Characterization of zein modified with a mild crosslinking agent, Ind Crops Prod. 20 (2004) 291-300.

[28] J.W. Mwangi, C.M. Ofner, Crosslinked gelatin matrices: release of a random coil macromolecular solute, Int. J. Pharm. 278 (2004) 319327.

[29] K. Tomihata, Y. Ikada, Cross-linking of hyaluronic acid with watersoluble carbodiimide, J. Biomed. Mater. Res. 37 (1997) 243-251.

[30] S. Drotleff, U. Lungwitz, M. Breunig, A. Dennis, T. Blunk, J. Blunk, J. Tessmar, A. Göpferich, Biomimetic polymers in pharmaceutical and biomedical sciences, Eur. J. Pharm. Biopharm. 58 (2004) 385407.

[31] S. Hirsch, V. Binder, V. Schehlmann, K. Kolter, K.H. Bauer, Lauroyldextran and cross-linked galactomannan as coating materials for site-specific drug delivery to the colon, Eur. J. Pharm. Biopharm. 47 (1999) 61-71.

[32] S. Park, H. Lee, Biological characterization of EDC-cross-linked collagen-hyaluronic acid matrix in dermal tissue restoration, Biomaterials 24 (2002) 1631-1641.

[33] S. Park, J. Park, H.O. Kim, M.J. Song, H. Suh, Characterization of porous collagen-hyaluronic acid scaffold modified by 1-ethyl-3-(3dimethylaminopropyl)carbodiimide crosslinking, Biomaterials 23 (2002) 1205-1212.

[34] R. Zeeman, P.J. Dijkstra, P.B. van Wachem, M.J.A. van Luyn, M. Hendriks, P.T. Cahalan, J. Feijen, Successive epoxy and carbodiimide cross-linking of dermal sheep collagen, Biomaterials 20 (1999) 921-931.

[35] S.B. Lee, H.W. Jeon, Y.W. Lee, Y.M. Lee, K.W. Song, M.H. Park, Y.S. Nam, H.C. Ahn, Bio-artificial skin composed of gelatin and $(1 \rightarrow$ 3), (1 $\rightarrow 6)-\beta$ glucan, Biomaterials 24 (2003) 2503-2511.

[36] P.L. Ritger, N.A. Peppas, A simple equation for description of solute release I. Fickian and non-fickian release from non-swellable devices in the form of slabs, spheres, cylinders or discs, J. Controlled Release 5 (1) (1987) 23-36. 
[37] S. Putthanarat, S. Zarkoob, J. Magoshi, J.A. Chen, R.K. Eby, M. Stone, W.W. Adams, Effect of processing temperature on the morphology of silk membranes, Polymer 43 (2002) 34053413.

[38] E. Kuduğ, Use of fibroin/hyaluronic acid matrices as a drug reservoir in iontophoretic transdermal delivery, MS Thesis, Izmir Institute of Technology, Izmir, Turkey, 2004.

[39] J. Magoshi, Y. Magoshi, M.A. Becker, M. Kato, Z. Han, T. Tanaka, S.-I. Inoue, S. Nakamura, Crystallization of silk fibroin from solution, Thermochimi Acta 352-353 (2000) 165-169.

[40] P.V. Parab, C.K. Oh, W.A. Ritschel, Sustained release from pecirol (glycerol palmito-stearate) matrix: effect of mannitol and hydroxpropyl methylcellulose on the release of theophylline, Drug Dev. Ind. Pharm. 12 (1986) 1309-1327.
[41] F. Lecomte, J. Siepmann, M. Walther, R.J. MacRae, R. Bodmeier, Polymer blends used for the aqueous coating of solid dosage forms: importance of the type of plasticizer, J. Controlled Release 99 (2004) $1-13$.

[42] Ö. Malay, A. Batıgün, O. Bayraktar, Cross-linked silk fibroin films in drug delivery applications, BIOMED 2004: 11th International Biomedical Science and Technology Days, 6-10 September 2004, Ankara-Turkey.

[43] Y. Özgarip, Application of silk fibroin in controlled-release of theophylline, MS Thesis, Izmir Institute of Technology, Izmir, Turkey, 2004.

[44] Y. Tsuboi, T. Ikejiri, S. Shiga, K. Yamada, A. Itaya, Light can transform the secondary structure of silk protein, Appl. Phys. A Mater. Sci. Process. 73 (2001) 637-640. 